\title{
Natural Fibre Modification and Its Influence on Fibre-matrix Interfacial Properties in Biocomposite Materials
}

\author{
S. O. Amiandamhen ${ }^{1,2 *}$, M. Meincken ${ }^{1}$, and L. Tyhoda ${ }^{1}$ \\ ${ }^{1}$ Department of Forest and Wood Science, Stellenbosch University, Stellenbosch 7602, South Africa \\ ${ }^{2}$ Department of Forestry and Wood Technology, Linnaeus University, Växjö 351 95, Sweden \\ (Received April 12, 2019; Revised September 16, 2019; Accepted September 20, 2019)
}

This article is published with open access at Springerlink.com

\begin{abstract}
Biocomposite materials manufactured from natural fibres and polymer matrix represent a group of engineered composite products with diverse applications. These materials continue to find increasing applications due to their design flexibility, superior properties and aesthetic appeal. The applicability of these biocomposites, however, depends on the interaction in the fibre-matrix interface. This paper reviews the state of the art research in fibre-matrix interfacial interaction based on published literature. A brief background on biocomposite materials is presented. The focus of this review is the modification of natural fibres and its effect on fibre-matrix interfacial adhesion and properties. In addition, the effect of chemical treatment on fibre composition and fibre-matrix interfacial bonding mechanism are discussed.
\end{abstract}

Keywords: Biocomposites, Fibre-matrix interface, Interfacial property, Natural fibres, Polymers

(C) The Author(s) 2020, corrected publication 2020

\section{Introduction}

Biocomposite materials that are durable and sustainable have been the subject of various research efforts for many decades. The demand for such products has been increasing over time, with new and innovative products that meet consumers' acceptance gaining market opportunities. Traditional biocomposite products utilizing different natural fibres and binder systems have been developed to adapt to various end-use applications. Natural fibres have been used in composite products since the beginning of human civilization, when straw was used to reinforce mud bricks in building applications. The continued interest in natural fibres is due to several advantages they offer when used as reinforcement in composite materials, as well as the potential environmental benefits. Some of these advantages include widespread availability, high stiffness and tensile strength, relatively low cost and well developed technology to extract fibres from renewable sources $[1,2]$. Natural fibres contain cellulose, hemicellulose, lignin, pectin, waxes and other water-soluble extractives. However, their use in biocomposite materials is faced with certain difficulties. The major limitations to the use of natural fibres in biocomposites include their sensitivity to moisture and variable fibre properties, coupled with the inherent incompatibility between the hydrophilic fibres and the hydrophobic matrix [3-5]. The extent of this limitation depends on the type of fibre, nature of the matrix and the fibre-matrix interaction. This incompatibility results in high moisture absorption and weak adhesion with the matrix. These limitations result in

*Corresponding author: stephen.amiandamhen@lnu.se inadequate fibre distribution and subsequently poor stress transfer from the matrix to the fibres $[3,6]$.

In order to overcome these limitations, different treatment strategies have been developed. One way is by surface modification of the fibres by removing constituents, which are not likely to affect the properties of the composites or changing the fibre structural composition in order to improve adhesion. Other ways include the use of compatibilizers or coupling agents to improve stress transfer from matrix to fibre. Several studies have been conducted regarding the modification of natural fibres for composite development [59] and different treatment methods have been applied in these studies. Physical methods do not change the structural composition of the fibres but modify the surface properties, thereby enhancing fibre-matrix adhesion. Chemical methods are the most widely developed and result in structural changes to fibres, enabling fibre-matrix interfacial bonding. Biological methods employ bacterial action on the fibre surface, resulting in significant improvement in interfacial adhesion with polymeric matrices.

This review discusses some chemical modification of natural fibres as a precursor for fibre applications in biocomposite productions. In addition, fibre-matrix interfacial bonding and property are discussed, as these ultimately characterise the resulting properties of the biocomposite material.

\section{Biocomposite Materials}

Biocomposites are a diverse group of materials that are increasingly utilized in many fields of interest including civil and construction engineering. One principal advantage of 
biocomposites is their flexibility to be designed to suit different industrial applications. Conventional wood-based biocomposite products are made with a thermosetting resin that binds lignocellulosic fibres together, with the exception of wood plastics and fibre cement composites, which use polymer resin and cement binder, respectively $[10,11]$. These groups of adhesives are chosen based upon their suitability for the product under consideration. The choice of adhesive to use for a particular biocomposite product depends on the materials to be bonded together, moisture content at time of bonding, mechanical property and durability requirements of the resultant composite products, and the cost of the resin [12]. The commonly used thermosetting adhesives are formaldehyde-based and include phenolformaldehyde (PF) and urea-formaldehyde (UF). While PF resin is used in the manufacture of biocomposite products durable in external conditions, UF is only suitable for interior applications [11]. The disadvantage with the use of these adhesives is the high energy consumption in processing of the adhesives and the health effect of formaldehyde emissions.

Thermoplastics are another group of binders used in the production of wood plastic composites. Usually, thermoplastics selected for use with natural fibres should melt at or below the thermal degradation temperature of the lignocellulosic material, which is normally $200-220^{\circ} \mathrm{C}[11,12]$. These thermoplastics include polypropylene (PP), polystyrene (PS), polyvinylchloride (PVC), and polyethylene (PE) (low and high density). PVC is substantially a harder material than the other polymers and PVC based composites are used as building materials. Inorganic binders have also been used extensively in the production of inorganic bonded wood and fibre composites. The most common inorganic binders include gypsum, magnesia cement and Portland cement. Gypsum and magnesia cement are moisture sensitive, and their use in construction is generally restricted to interior applications [10,13]. Composites bonded with Portland cement are more durable and are suitable for both interior and exterior applications. In recent years, there has been an increased interest in developing a new class of inorganic biocomposites using phosphate based binders [14]. High early strength chemically bonded phosphate ceramic binders have been used to manufacture wood and fibre products with properties comparable to that of Portland cement $[15,16]$.

\section{Preparation of Biomaterials with Natural Fibres}

Natural fibres have been extensively used in the preparation of biocomposite materials for building and constructions and other applications such as sports, automotive and aircraft components [17-19]. The basic raw material for particleboard production is mill residue, such as sawdust, planer shavings and chips and a variety of agricultural residues, including wheat straw, rice husks, jute and cotton stalk. Low-density insulating or sound absorbing particleboard can be made from kenaf core or jute sticks.
Low, medium and high-density panels can be produced with cereal straw and rice husks [10]. Materials for oriented strand board (OSB), wafer board and fibre board are obtained from wood flakes or chips. However, in the production of fibre board, the chips are reduced to wood fibres using refiners. Wood flour and wood fibre are the primary raw materials used in the production of wood plastic composites. Wood flour is used as filler in thermoplastic composites, while wood fibres act more as reinforcement and lead to superior composite properties. Usually, several additives are used to enhance the performance of wood thermoplastic composites. These materials are known as compatibilizers and can improve bonding between the thermoplastic and wood component [20,21]. Other additives can be added to improve product performance, such as impact modifiers, UV light stabilizers, or flame retardants and process ability (lubricants) [12].

The raw materials for wood cement composites are typically wood particles and fibres for high-density products, while wood excelsior is used in the manufacture of lowdensity wood cement composites. The use of pulp fibres offers numerous advantages when compared to other fibre reinforced cement composites [1]. Several researchers have demonstrated the suitability of different non-wood fibres in the production of fibre cement composites [22,23]. Gypsum bonded composites have also been produced with different wood based fibres including paper mill sludge, virgin pulp and sawdust [24-26].

Generally, most natural fibres can be used to manufacture different biocomposite products. The main consideration is the composition of such fibres as this determines some fundamental properties of the biocomposites. A knowledge of the chemical composition of natural fibres and their adhesive surface properties is important in order to develop any biocomposite material [27].

\section{Fibre Chemical Composition}

The main constituents of natural fibres are cellulose, hemicellulose and lignin. Natural fibres also contain pectin, waxes and other water-soluble extractives. The holocellulose (cellulose and hemicellulose), sugars and lignin contents are of major importance in biocomposite development. The chemical composition of some selected fibres is presented in Table 1. Cellulose is made up of D-glucopyranose units linked together by $\beta-(1-4)$-glucosidic bonds (Figure 1(a)). Due to the large proportion of hydroxyl groups within the cellulose structure, there is a high affinity for moisture, which generally affects the dimensional stability of fibrematrix composites. However, cellulose has a positive correlation with the strength, elastic properties and physical characteristics of fibres [5]. Hemicellulose polymers are the most hydrophilic wood constituents and are partly soluble in water [28] (Figure 1(b)). They are fully amorphous and are 
Table 1. Chemical composition of some selected fibres

\begin{tabular}{lccccc}
\hline \multicolumn{1}{c}{ Source } & Cellulose (\%) & Hemicelluloses $(\%)$ & Ash $(\%)$ & Lignin $(\%)$ & References \\
\hline Pine & $40-49$ & $26.9-28.5$ & 0.3 & $27-27.7$ & {$[3,72,73]$} \\
Eucalyptus & $45-62.6$ & $15.7-19.2$ & $0.3-0.36$ & $21.6-33.9$ & {$[74,75]$} \\
Hemp & $67-74.4$ & $16-22.4$ & $2.1-2.6$ & $3.3-5.7$ & {$[6,76,77]$} \\
Kenaf & $53-63.5$ & $15-19$ & $2.2-4.7$ & $5.9-12.7$ & {$[78,79]$} \\
Bagasse & $34.9-55.4$ & $16-29$ & $1.1-2.9$ & $21.4-25.3$ & {$[3,80-82]$} \\
Triticale & $38-49.1$ & $26.1-30$ & 4.5 & $15.9-20$ & {$[83,84]$} \\
Kraft paper sludge & $41.4-57.1$ & $8.1-11.23$ & 49.1 & $20.3-27.4$ & {$[85,86]$} \\
Black wattle & 63.9 & 12.7 & 0.47 & $17.9-21.2$ & {$[3,87,88]$} \\
\hline
\end{tabular}

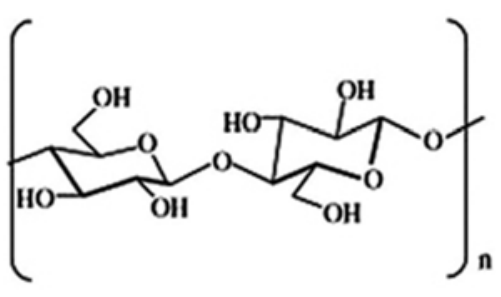

(a)

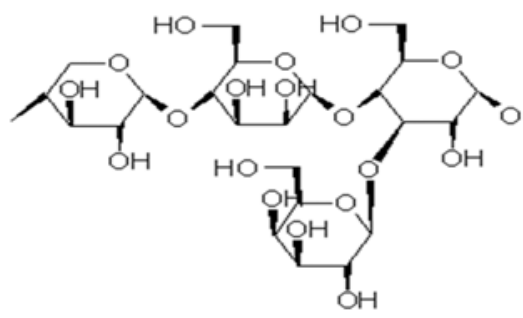

(b)

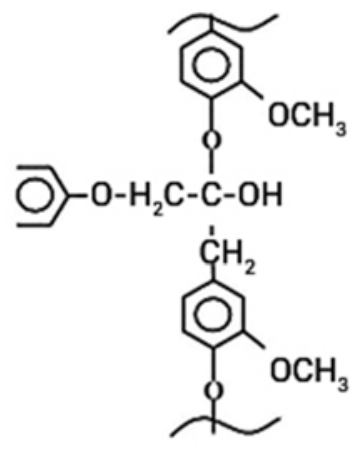

(c)

Figure 1. Chemical structure of the main components of natural fibres (a) cellulose, (b) hemicellulose, and (c) lignin [94].

strongly bound to cellulose fibrils presumably by hydrogen bonds [27]. Although, many treatments of natural fibres are directed toward removing the hemicelluloses, it has been found that hemicellulose removal negatively affects some wood properties [5,29,30]. Lignin is a highly complex and aromatic polymer of phenyl propane units (Figure 1(c)). It is amorphous and binds the crystalline celluloses with the hemicelluloses within the cell wall. Klüppel and Mai [31] demonstrated that while hemicellulose improves wood strength in dry conditions, lignin maintains wood strength in wet conditions. However, lignin content was found to have a negative correlation with fibre physical and mechanical properties in some natural fibres [5].

With the knowledge of the chemical composition of natural fibres, researchers are able to systematically select fibres of interest to utilize in biocomposite production. However, it may be possible to utilize different fibre materials as long as there are methods to improve the fibrematrix compatibility of the biocomposite. In order to optimize and maximize the interfacial bonding between fibre and matrix, several fibre surface modification techniques have been addressed.

\section{Fibre Surface Modification}

The production of biocomposite materials presents certain difficulties due to the natural incompatibilities between lignocellulosic fibres and matrix. The use of methods that can alter the physical, chemical or morphological properties of the fibres is imperative to make hydrophilic natural fibres bond well to highly polar hydrophobic polymers. As already stated, the major limitation to the use of natural fibres is that they are unstable in the presence of moisture leading to weak adhesion with the polymer. In addition, the presence of waxes and pectin in the cell wall prevents the interlocking with the matrix by covering the reactive functional groups of the fibres. The combined effect of this inaccessibility is a poor adhesion across the phase boundary and a resultant weak dispersion of force and poor strength properties $[32,33]$. Consequently, natural fibres have been treated to reduce the hydrophilic sites and improve the adhesion to matrix materials. Several treatment strategies have been developed; this includes physical, chemical and biological treatments.

Physical fibre modification does not change the structural composition of the fibres, but modifies the surface properties. This results in improved mechanical bonding with the matrix, hence improved composite properties [34]. On the contrary, Cruz and Fangueiro [9] reported that physical treatment changes the structural and topological properties of the fibre, thereby increasing the strength of the fibres. Some physical treatments include stretching, calendaring, 
cold plasma treatment, electric discharge and thermotreatments. Plasma treatment has been successfully used to modify the surface of various natural fibres. After plasma treatment, mechanical properties of natural fibres were found to improve significantly. Additionally, plasma treatment can introduce various functional groups on the natural fibre surface, which form strong covalent bonds with the matrix, thereby resulting in strong fibre-matrix interface [35]. Similarly, plasma treatment, which induces surface etching may improve the surface roughness and result in a better interface with the matrices through mechanical interlocking [9].

Biological methods for fibre modification have also great potential to improve interfacial adhesion. The presence of cellulose nanofibrils deposited on the surface of sisal and hemp fibres, used as substrates during fermentation process showed some bacterial activities. It was observed that the deposition of about 5-6\% bacterial cellulose on the natural fibre surface resulted in significant improvement in interfacial adhesion with polymeric matrices such as polylactic acid and cellulose acetate butyrate [9]. Chemical methods are the most widely developed and result in structural changes of the fibres, improving fibre-matrix interfacial bonding. Natural fibres have been treated with various chemicals, such as alkali, silane, acetic anhydride and peroxides [3,6,27]. These treatments have been reported to significantly improve the mechanical properties of natural fibres by modifying their crystalline structure, as well as removing weak components, like hemicelluloses from the fibre surface [27]. The overall effect of this modification is improved interfacial adhesion between fibres and matrix. Some chemical modification methods and their influence on chemical composition, as well as fibre-matrix interfacial adhesion are discussed further.

\section{Chemical Treatments of Natural Fibres}

Chemical treatment may activate functional hydroxyl groups and/or introduce new moieties that can bridge the fibre and the matrix. Typically, the introduction of coupling agents, such as in wood-polymer composites bridge the hydroxyl group of the fibres and the functional groups of the matrix $[27,36]$. The result is the development of a highly cross-linked interface region with an intermediate modulus between that of substrate and polymer and the formation of covalent bonds. Different chemical treatments have been reported in literature. Hot water extraction is the cheapest and oldest means of structurally modifying the composition of natural fibres. Hot water extraction is a thermochemical process for the fractionation of soluble sugars [37]. During the hydrolysis, hemicelluloses are depolymerized into monomers and oligomers. Cellulose may be partially depolymerized, while lignin may be subjected to plasticization, partial solubilisation, condensation or depolymerisation [38]. The combined reactions change the composition and properties of the resultant fibres. By removing the

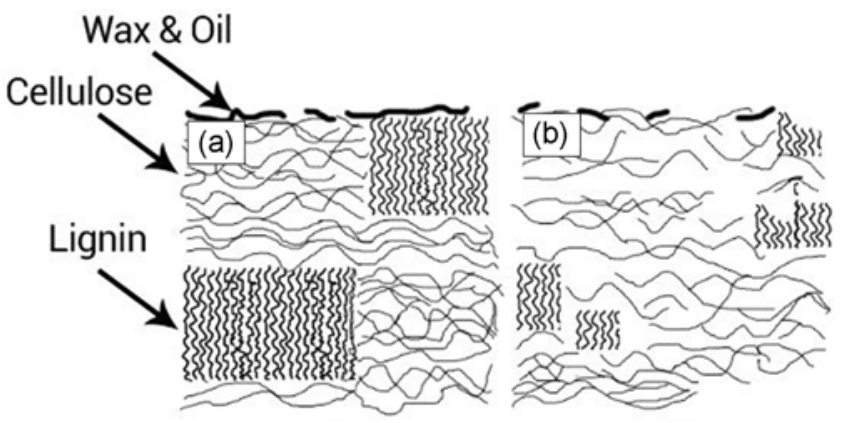

Figure 2. Schematic representation of a natural fibre showing (a) untreated and (b) alkaline treated [94].

hemicelluloses, the amount of available hydroxyl groups in the fibres is reduced, leading to increased resistance to moisture uptake, dimensional stability and durability of composites [28].

The most common is the alkaline treatment using sodium hydroxide, which alters the structural orientation of the highly crystalline cellulose order and forms amorphous regions by swelling the fibre cell wall $[8,32]$. The alkaline treatment promotes the ionization of the hydroxyl group to the alkoxide as shown;

Fibre $-\mathrm{OH}+\mathrm{NaOH} \rightarrow$ Fibre $-\mathrm{O}-\mathrm{Na}+\mathrm{H}_{2} \mathrm{O}$

Alkaline sensitive hydrogen bonds break down resulting in the formation of new hydrogen bonds between the molecular cellulose chains. This treatment also removes a certain amount of hemicellulose, lignin, wax and oil covering the external surface of the fibre cell wall (Figure 2) $[3,27,34]$. The factors affecting alkalization or alkaline treatment are the type and concentration of alkali, treatment time and temperature [6]. Different conditions have been used by different authors, ranging from $0.5 \%$ to $29 \%$ $\mathrm{NaOH} ; 20$ min to $8 \mathrm{~h}$ and from room temperature to $120{ }^{\circ} \mathrm{C}$ $[3,39,40]$. The concentration of the alkali should not be higher than the optimum condition; otherwise excess delignification will result in weaker and damaged fibres [41].

Another widely adopted fibre treatment is acetylation with acetic anhydride. This method introduces an acetyl functional group $\left(\mathrm{CH}_{3} \mathrm{COO}^{-}\right)$into the fibres by substituting the polymer hydroxyl groups of the cell wall, causing plasticization of cellulose [27]. The reaction of acetic anhydride with the fibre is shown as;

$$
\begin{gathered}
\text { Fibre }-\mathrm{OH}+\mathrm{CH}_{3}-\mathrm{C}(=\mathrm{O})-\mathrm{O}-\mathrm{C}(=\mathrm{O})-\mathrm{CH}_{3} \rightarrow \\
\text { Fibre }-\mathrm{O}-\mathrm{C}(=\mathrm{O})-\mathrm{CH}_{3}+\mathrm{CH}_{3} \mathrm{C}(=\mathrm{O})-\mathrm{OH}
\end{gathered}
$$

Acetylation can be carried out with or without an acid catalyst. Usually, acetic anhydride and acetic acid individually do not react sufficiently with cellulosic fibres. As a result, the fibres are initially soaked in acetic acid before being treated with acetic anhydride between 1 to $3 \mathrm{~h}$ at slightly elevated temperatures [32]. Other authors use ratios of 1:1 or 
$1: 1.5$ of acetic anhydride to acetic acid $[3,6]$. This treatment swells the fibre cell wall [42] resulting in decreased hydrophilicity and improvement in dimensional stability of the composites $[6,43]$. Acetylation provides a rough surface topography with fewer voids in the fibre cell walls, resulting in better mechanical interlocking with the matrix [3,27]. Figure 3 shows scanning electron microscopy (SEM) images of natural fibres before and after different chemical treatments [3].

Other chemical treatments to modify natural fibres have been reported, such as salinization, which stabilizes composite materials by incorporating silane-coupling agents to modify the fibre surface. Silanols, formed in the presence of moisture from hydrolysable alkoxyl groups react with cellulose hydroxyl groups to form stable covalent bonds to the cell wall $[6,27]$.

Fibre $-\mathrm{OH}+\mathrm{R}-\mathrm{Si}(\mathrm{OH})_{3} \rightarrow$ Fibre $-\mathrm{O}-\mathrm{Si}(\mathrm{OH})_{2}-\mathrm{R}$

Benzoylation improves fibre matrix adhesion, resulting in increased composite strength, improved thermal properties and decreased moisture sensitivity. Benzoylation uses benzoyl chloride, which includes benzoyl $\left(\mathrm{C}_{6} \mathrm{H}_{5} \mathrm{C}=\mathrm{O}\right)$. Benzoyl is responsible for decreased hydrophilic nature of treated fibres and improved interaction with the hydrophobic matrix [27].

Fibre $-\mathrm{O}-\mathrm{Na}+\mathrm{C}_{6} \mathrm{H}_{5}-\mathrm{COCl} \rightarrow$ Fibre $-\mathrm{O}-\mathrm{CO}-\mathrm{C}_{6} \mathrm{H}_{5}+\mathrm{NaCl}$
Acrylic acid and acrylonitrile can be used to modify fibres by graft polymerization. Maleic anhydride can also be used to modify natural fibre surfaces to achieve better interfacial bonding and mechanical properties in composites. The reaction scheme as presented by Zhou et al. [44] is shown as;

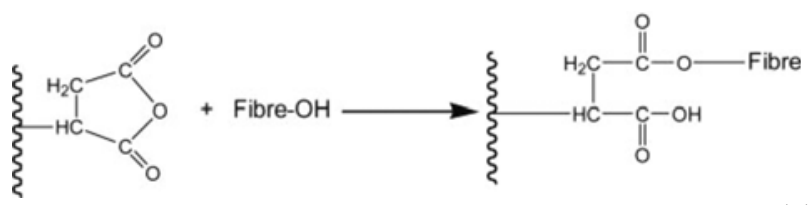

Other treatments of natural fibre surfaces involve the use of potassium permanganate $\left(\mathrm{KMnO}_{4}\right)$ solution in acetone, peroxides, isocyanate, stearic acid $\left(\mathrm{CH}_{3}\left(\mathrm{CH}_{2}\right)_{16} \mathrm{COOH}\right)$ in ethyl alcohol, sodium chlorite $\left(\mathrm{NaClO}_{2}\right)$ and triazine $\left(\mathrm{C}_{3} \mathrm{H}_{3} \mathrm{~N}_{3}\right)$ [27]. It was reported that the flexural strength of treated fibres increased owing to the lower stiffness and higher flexibility of fibres after delignification with sodium chlorite [4]. Table 2 presents some chemical modification methods for different natural fibres and their use in biocomposite production.

\section{Chemical Treatment and Its Effect on Fibre Composition}

Amiandamhen et al. [3] showed the effects of mild processes of alkalization, acetylation and hot water treatments on the chemical composition of selected natural fibres used
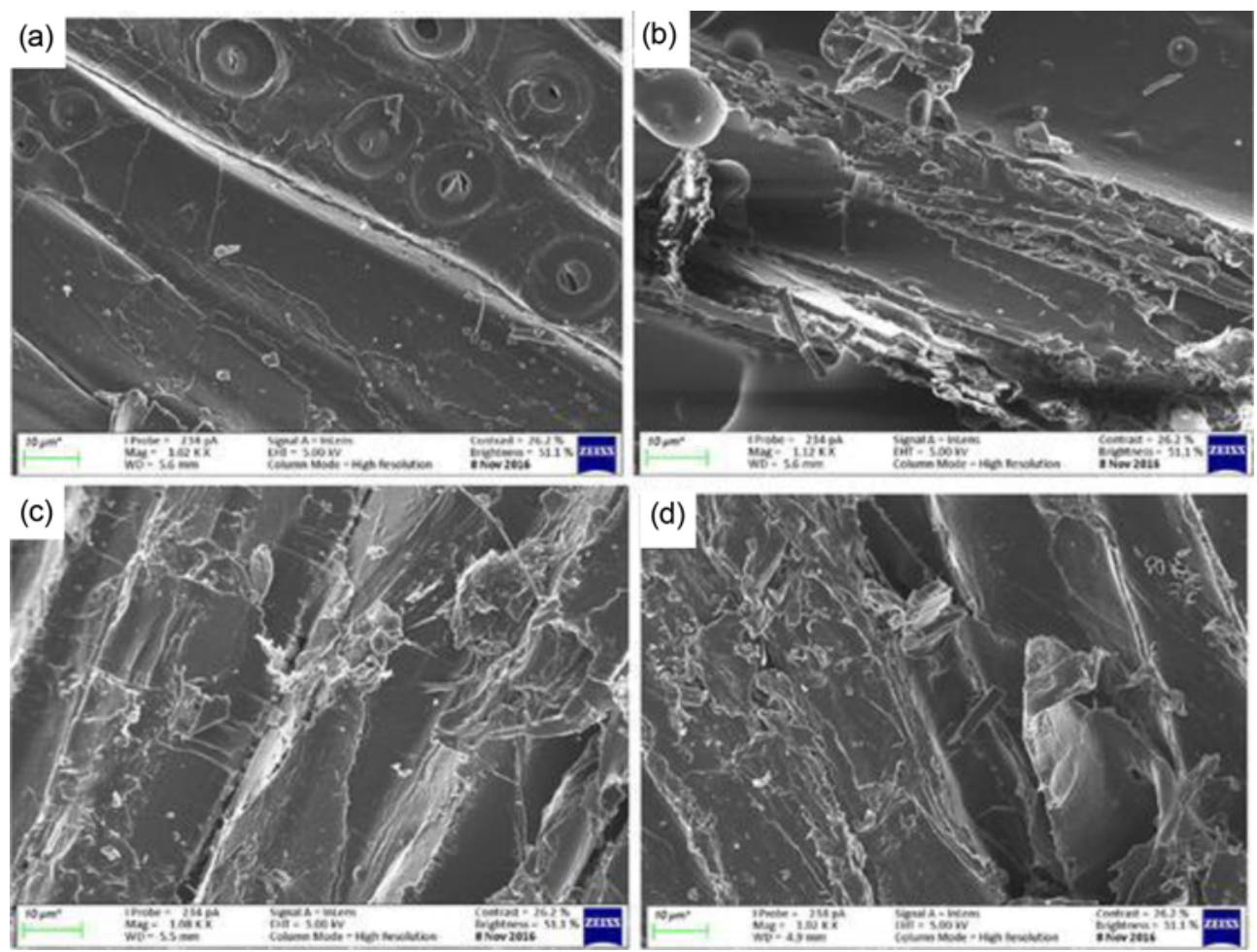

Figure 3. SEM images showing surfaces of (a) untreated, (b) hot water treated, (c) acetylated, and (d) alkalised wood fibres [3]. 
Table 2. Chemical treatment of natural fibres and its effect on interfacial property

\begin{tabular}{|c|c|c|c|c|}
\hline Fibre source & Treatment type & Polymer type & Remarks & References \\
\hline Softwood & Acetylation & PLA & The interfacial stress transfer ability was improved in treated composites & [60] \\
\hline Pineapple leaf & Alkali + silane & Polyamide 6 & $\begin{array}{l}\text { Alkali treatment was sufficient to improve the compatibility and proper- } \\
\text { ties of the composites at fibre loading of } 30 \% \mathrm{wt} \text {. }\end{array}$ & [89] \\
\hline Sisal & $\begin{array}{l}\text { Alkali }+ \text { cold plasma } \\
+ \text { starch nanocrystals }\end{array}$ & Starch & Tensile and interfacial shear strengths were significantly improved & {$[69]$} \\
\hline Sisal & MAPE & HDPE & $\begin{array}{l}\text { The interfacial and dynamic mechanical properties were improved after } \\
\text { modification }\end{array}$ & {$[49]$} \\
\hline Bamboo & Alkali & Epoxy & $\begin{array}{l}\text { Interfacial shear strength increased after treatment at } 4 \% \mathrm{NaOH} \text { concen- } \\
\text { tration, but decreased after } 7 \% \text { alkali treatment }\end{array}$ & [68] \\
\hline Kenaf & $4 \% \mathrm{HCl}$ & Polyurethane & $\begin{array}{l}\text { Tiny hollow spots were observed on fibre surfaces which caused stress } \\
\text { concentrations during pull-out }\end{array}$ & {$[90]$} \\
\hline Wood & $\begin{array}{l}\text { Coupling agents } \\
\text { (BMI, DBMI) }\end{array}$ & PLA & $\begin{array}{l}\text { The two compounds improved the interfacial properties of the biocom- } \\
\text { posites; however, DBMI was found to be more effective than BMI as a } \\
\text { coupling agent. }\end{array}$ & {$[48]$} \\
\hline Typha & Alkali & Epoxy & $\begin{array}{l}\text { Interfacial compatibility between fibre and matrix was improved } \\
\text { following } 5 \% \text { alkali treatment }\end{array}$ & [19] \\
\hline Flax/cotton yarns & Alkali/peroxide & Polyester/PLA & $\begin{array}{l}\text { Alkalization improved the biocomposite interfacial strength while } \\
\text { bleaching had no significant effect on the composites. }\end{array}$ & [71] \\
\hline Jute & Alkali + silane & PLA & $\begin{array}{l}\text { The interfacial adhesion and shear strength were improved after treat- } \\
\text { ment }\end{array}$ & {$[66]$} \\
\hline Kenaf & Alkali & Epoxy & $\begin{array}{l}\text { The interfacial shear strength increased after } 2 \% \mathrm{NaOH} \text { treatment } \\
\text { compared to untreated composites }\end{array}$ & [91] \\
\hline Wood/rice husk & MAPP & Polypropylene & $\begin{array}{l}\text { The treated composites showed improved interfacial adhesion, } \\
\text { mechanical properties and thermal stability. }\end{array}$ & [92] \\
\hline Bamboo & $\begin{array}{l}\text { Micro-fibrillated } \\
\text { cellulose }\end{array}$ & PLA & $\begin{array}{l}\text { Fracture toughness and interfacial adhesion were significantly improved } \\
\text { even when } 10 \% \text { wt. of MFC was added to the bamboo/PLA composite }\end{array}$ & [93] \\
\hline
\end{tabular}

MAPE: maleic anhydride polyethylene, HCl: hydrochloric acid, BMI: N,N-(1,3-phenylene dimaleimide), DBMI: 1,1-(methylenedi-4,1-phenylene) bismaleimide, MAPP: maleic anhydride polypropylene, PLA: poly(lactic acid), and HDPE: high density polyethylene.

in biocomposite production (Table 3). All treatments reduced the lignin content in the fibres, but the effect was less in hot water treated fibres. Hot water extraction also reduced the total xylose and glucose in black wattle fibres. The authors further confirmed their result with FTIR analysis. Alkalization was observed to proportionally increase the ash content of the fibres, probably due to the removal of organic matter, which proportionally increases the percentage of the inorganic materials. It was observed that there was a proportional gain in the lignin content of bagasse fibres after hot water treatment. This gain could be due to the tendency of lignin to be depolymerized and condensed in a different morphology during hemicelluloses hydrolysis [38,45]. The glucose and xylose contents were proportionally increased in pine fibres due to the pretreatments, which removed some lignin from the fibres. Alkalization also proportionally increased the xylose and glucose contents in bagasse fibres due to the removal of lignin. Alkalization had the greatest effect on the lignin content of bagasse fibres with a percentage reduction of $42.26 \%$. HPLC test conducted for other types of sugars did not return any result [3].
Other studies have been carried out on the effect of chemical pretreatment on constituent extraction in biomass. In one report, Carvalho et al. [46] used cold alkaline extraction for bioethanol production from eucalyptus, sugarcane bagasse and sugarcane straw. They found that the pretreatment removed $46 \%, 52 \%$ and $61 \%$ of the xylan and $15 \%, 37 \%$ and $45 \%$ of the lignin for eucalyptus, bagasse and straw, respectively. Vena et al. [47] studied the hemicelluloses extraction from giant bamboo (Bambusa balcooa Roxburgh) prior to kraft or soda-AQ pulping and its effect on pulp physical properties. They found that xylan removal was 13.6 and $20.4 \%$ for 1 and $2 \mathrm{M} \mathrm{NaOH}$ solution, respectively. For dilute acid preextraction, about $11.3 \%$ xylan could be removed without affecting pulp quality [47]. These studies showed that it is possible to extract certain components from natural fibres, thereby increasing the utilization potential of the products. One benefit of fibre chemical treatment is that the extracts could be used for other fields of interest such as biofuels, while the treated fibres could be desirable for many fibre-based applications such as in biocomposites. 
Table 3. Chemical composition of untreated and treated fibres with their percentage losses (\%) [3]

\begin{tabular}{|c|c|c|c|c|c|c|c|}
\hline Fibres & Treatment & Lignin & Glucose & Xylose & Lignin loss & Glucose loss & Xylose lose \\
\hline \multirow{4}{*}{ Wattle } & Untreated & $18.17 \pm 1.0$ & $42.73 \pm 5.0$ & $10.81 \pm 1.31$ & & & \\
\hline & Hot water & $17.42 \pm 3.63$ & $40.14 \pm 0.48$ & $10.09 \pm 0.15$ & 4.12 & 6.06 & 6.66 \\
\hline & Acetylation & $17.71 \pm 2.50$ & $41.84 \pm 1.17$ & $9.96 \pm 0.53$ & 2.53 & 2.08 & 7.86 \\
\hline & Alkalization & $16.07 \pm 4.32$ & $42.95 \pm 0.40$ & $9.79 \pm 0.23$ & 11.56 & $0.5^{*}$ & 9.44 \\
\hline \multirow{4}{*}{ Pine } & Untreated & $27.32 \pm 1.40$ & $36.29 \pm 0.92$ & $12.07 \pm 0.29$ & & & \\
\hline & Hot water & $26.31 \pm 1.25$ & $38.36 \pm 2.46$ & $12.47 \pm 0.87$ & 3.70 & $5.70 *$ & $3.31 *$ \\
\hline & Acetylation & $25.02 \pm 0.97$ & $41.54 \pm 0.05$ & $13.75 \pm 0.30$ & 8.42 & $14.47^{*}$ & $13.92 *$ \\
\hline & Alkalization & $25.27 \pm 0.94$ & $44.08 \pm 1.08$ & $14.07 \pm 0.49$ & 7.50 & $21.47 *$ & $16.57^{*}$ \\
\hline \multirow{4}{*}{ Bagasse } & Untreated & $23.33 \pm 4.17$ & $40.20 \pm 0.79$ & $11.40 \pm 0.29$ & & & \\
\hline & Hot water & $23.56 \pm 3.32$ & $39.07 \pm 1.66$ & $10.62 \pm 0.29$ & $1.0^{*}$ & 2.81 & 6.84 \\
\hline & Acetylation & $21.66 \pm 0.93$ & $37.41 \pm 2.44$ & $10.45 \pm 0.58$ & 7.16 & 6.94 & 8.33 \\
\hline & Alkalization & $13.47 \pm 2.72$ & $48.68 \pm 4.22$ & $15.00 \pm 2.85$ & 42.26 & $21.09^{*}$ & $31.6 *$ \\
\hline
\end{tabular}

Values represent mean of three replicates and standard deviation. $*$ : represents percentage proportional gain after pretreatment.

It was reported that natural fibre modifications resulted in improved biocomposite properties, owing to better fibrematrix interfacial adhesion $[19,48,49]$. The adhesion between fibre and matrix influences the interfacial property, which ultimately influences the biocomposite properties.

\section{Fibre-matrix Interfacial Property}

The fibre-matrix interface is the diffusion zone, in which the fibre and the matrix phases are connected either chemically or mechanically [32]. The most significant interfacial properties required to develop durable biocomposite materials are the debond fracture surface energy (DFSE) $G_{i}$ and the interfacial shear stress (IFSS) $\tau$. For a biocomposite material to be non-brittle, $G_{i}$ must be less than the fibre fracture surface energy (FFSE) $G_{f}$. If $\tau$ is too high, matrix micro cracking level may approach ultimate tensile strength. This shortens the fibre pull out lengths and the biocomposite becomes brittle. If $\tau$ is too low, the transfer of load from matrix to fibre will also be low. The result is a low micro cracking stress, low ultimate strength and less effort on fibre pull out [50].

Several techniques have been used to study the interfacial micromechanical properties of fibre and matrix. For any technique to be successful in biocomposite development, it must measure the IFSS $\tau$, DFSE $G_{i}$ and be applicable to a large range of fibre and matrix types with minimal, nonspecialized specimen preparation [50]. A number of the techniques rely on the tensile loading of a bar and measuring different parameters [51,52]. Some techniques use small cut samples from actual components while others involve the pushing or pulling of individual fibres within the matrix and measuring the applied load and fibre displacement [53-56]. In the single pull-out test (Figure 4), the fibre is pulled out of the matrix with an increasing load and the displacement is

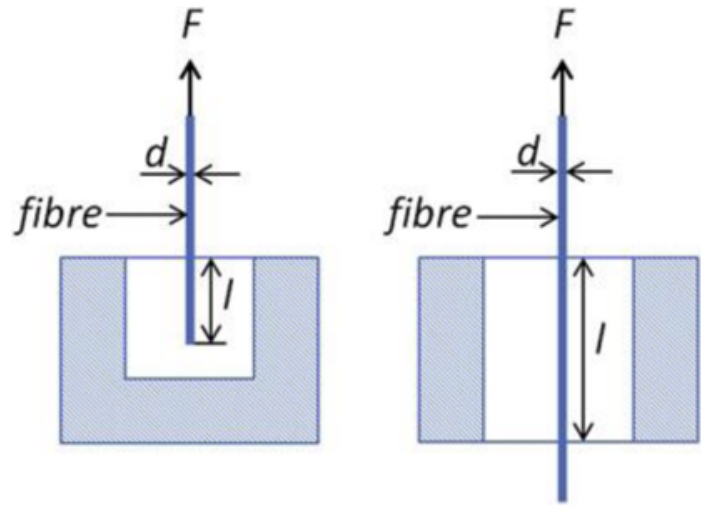

Figure 4. Schematic of single fibre pull-out test [44].

measured. Initially, the induced shear stresses along the fibre orientation do not exceed the interfacial bond strength. As soon as the pull-out load is determined, the IFSS can be calculated [44].

The maximum load, $F$, measured before the fibre is detached is related to the mean value of $\tau$, and is given by the equation;

$$
F=\tau \pi d l
$$

where $\pi d$ is the fibre circumstance and $l$ is the embedded fibre length [44].

Another technique using a stress contour of composite matrix was reported by Budiman et al. [57]. The authors used a developed single-fibre fragmentation test model to simulate the stress contour and the interface was modelled as a cohesive zone model. Koyanagi et al. [58] used bulk composite test to obtain interfacial properties between fibre and polymer matrix. The time and temperature dependence of the interface strength and the interface failure envelope under a combined stress state were evaluated. However, 
many of the techniques are applied in high performance synthetic fibre-reinforced matrix composites, probably owing to the low tensile modulus of some natural fibres in such applications and the weak interfacial adhesion to the matrix. A major limitation is the difficulty in characterizing wood-matrix interfacial property using the pull-out tests. This is most likely due to the small dimension of wood fibres.

Kamke et al. [59] modelled the micromechanical behaviour of the wood fibre-matrix interface, and integrated the microstructure of the interface region studied with an $\mathrm{X}$-ray micro-computed tomography (XCT). The model provided a $3 \mathrm{D}$ representation of equivalent strain and stress of the adhesive bond under an applied load and was validated using a lap-shear test [59]. The simulation results compared favourably with measured surface displacements with spatial resolution in the micron range. Measurement of strain development validated the efficiency of the model as a tool to analyse cellular structure and adhesive penetration. Going forward, the model can be adequate to predict stressstrain relationships inside the bond interface and to assess adhesive penetration and polymer properties on the performance of adhesive bonds [59]. Joffre et al. [60] proposed another method using acetylated wood fibres sticking out of the polylactic acid (PLA) matrix at the fracture surface. The length distribution of the fibres was approximated using XCT. This was then used to estimate the interfacial adhesion between the fibres and the matrix [60]. The authors found that acetylation treatment of the fibres improved their dimensional stability, and strength of the composite samples soaked in water by more than $30 \%$. In addition, the fibres did not lose their adhesion to the PLA matrix, thereby enhancing better stress transfer [60]. As a result, the fibre matrix interface could redistribute stresses during crack propagation, which improved the fracture toughness and the strength of the material.

\section{Fibre-matrix Interfacial Bonding}

Although the incorporation of natural fibres in polymer matrix results in enhanced biocomposite properties, poor interfacial bonding between natural fibres and matrix can affect composite properties, and hence composite durability [13]. This region of connection influences the mechanical properties of the composites, because the interfacial bonding between fibres and matrix characterises many biocomposite materials. Within a fibre-matrix system, it is possible to tailor the interfacial bonding practically by developing interfaces from matrix-fibre reaction during fabrication and the coating of fibres before they are incorporated into the matrix [50]. During stress transfer between matrix and fibres, good interfacial bonding allows the composites to carry load to a higher strain limit, although strong interface enables crack propagation, which ultimately reduces toughness and strength.

Studies on fibre-matrix interfacial bonding in paper cement composites using the SEM showed that the matrix covered the fibres adequately and can be pulled out together with the fibres during tensile fracture (Figure 5). This indicates that there is good adhesion between the fibres and matrix. In another study using maleic anhydride grafted polyethylene (MAPE), SEM was conducted on tensile fractured untreated and treated sisal fibre reinforced highdensity polyethylene (HDPE) composites. A large number of gaps resulting from fibre pull-outs were observed for the untreated composites compared to the MAPE treated composites (Figure 6). This was explained by poor interfacial adhesion and inadequate wetting of the untreated fibres within the HDPE matrix, owing to large differences in the surface energies between the fibres and the matrix [49]. Chi and Englund [61] investigated the interfacial bonding properties between magnesium phosphate cement and sugar maple (Acer saccharum). The authors used mixture design analysis to evaluate the magnesium phosphate ceramic (MPC)/maple interfacial shear properties with different aggregate levels. Portland cement, wollastonite and vitrified calcium alumina-silicate (VCAS) were used as aggregates within the system. Binder level was the most influential determinant of the interfacial property while cement decreases the interfacial bond strength. However, wollastonite
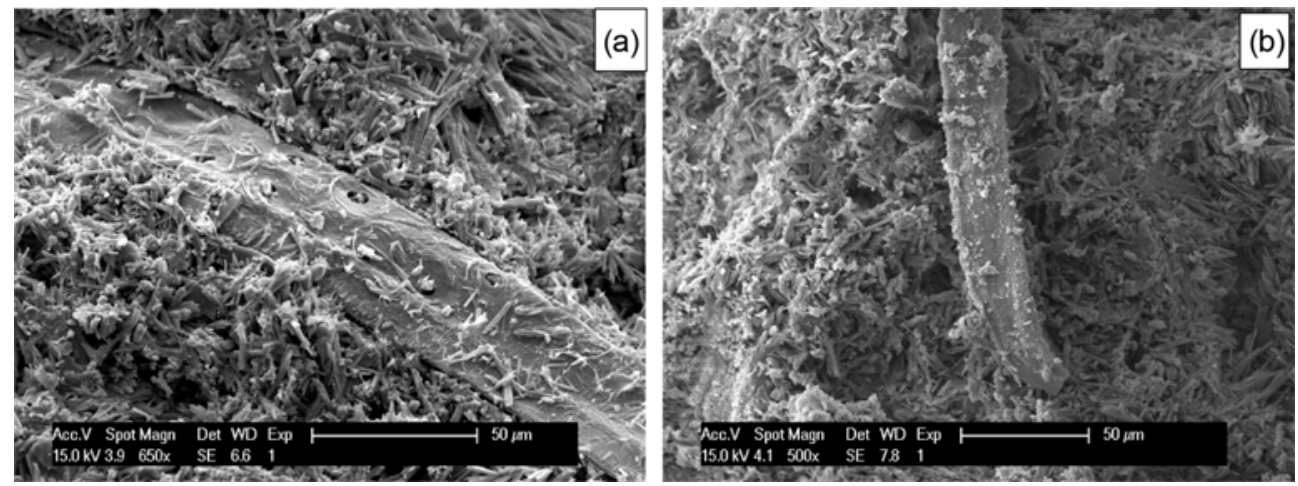

Figure 5. SEM images showing (a) natural fibre-matrix interface and (b) fibre pull out at matrix interface. 

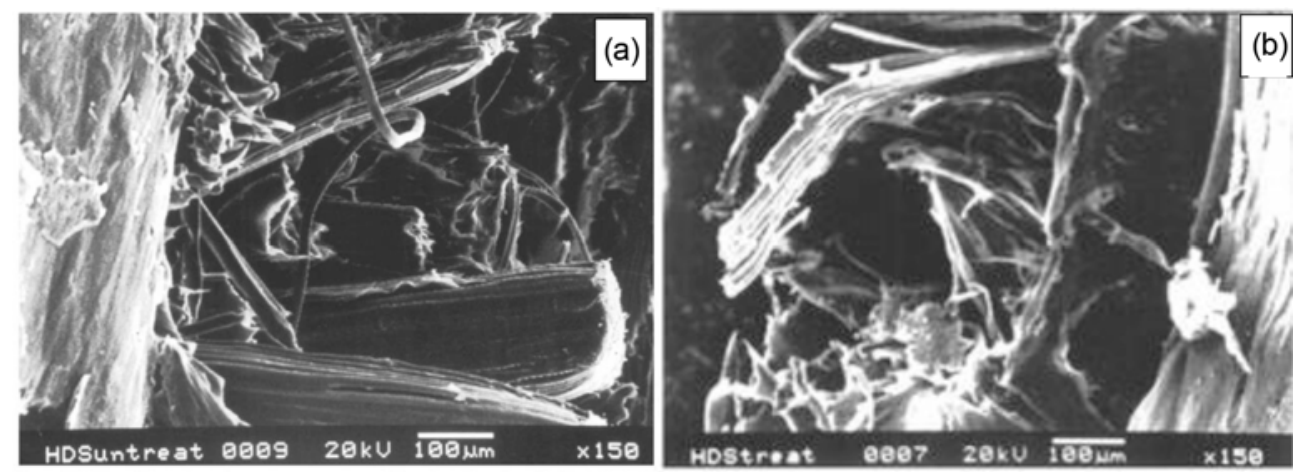

Figure 6. SEM micrographs of sisal fibre reinforced HDPE composites (a) untreated and (b) MAPE treated [49].

and VCAS mutually improved the interfacial properties. Based on fracture surface analysis, MPC block split failure and MPC/maple interfacial bond failure were identified and were correlated with the binder level and interfacial strength [61].

\section{Interfacial Bonding Mechanism between Fibre and Matrix}

As already discussed, the micromechanical property of composites is a function of the fibre, matrix and interface, with the interface having the major influence on the composite properties. The interface is a zone of compositional, structural and property gradients, which varies from a single atom layer to micrometres in width [44]. At the interfacial zone, several interactions occurring on the atomic, microscopic and macroscopic levels are closely related. Interfacial bonding mechanism usually occurs by mechanical interlocking, electrostatic bonding, chemical bonding and inter-diffusion bonding [62]. Mechanical interlocking occurs when the fibre surface is rough, and the matrix penetrates into the peaks, valleys and crevices or other irregularities of the substrate, and mechanically locks to it [44]. This increases the interfacial shear strength, but has less influence on the transverse tensile strength [33]. It happens on a millimetre and micron length scale, and diffusion entanglement within the cell wall pores of fibre occurs on a nanoscale [44]. The influence of electrostatic bonding is only significant and applicable in metallic interfaces. Electrostatic adhesion creates opposite charges (anionic and cationic) on the interfacial zone. Thus, a two-layer zone of opposite charges is formed, which determines the interfacial adhesion.

Chemical bonding occurs when there are chemical groups in the phase boundary that can react to form chemical bonds. In this instance, the resultant interfacial strength depends on the type and density of the bonds [33]. This type of bonding can be achieved when a coupling agent is used as a bridge between the fibre and matrix. Chemisorption occurs when chemical bonds including atomic and ionic bonds are created at the fibre matrix interface due to a chemical reaction. Physical and chemical bonds depend on the surface chemistry of the substrate and are sometimes described as thermodynamic adhesion [44]. Lastly, inter-diffusion bonding occurs when atoms and molecules of the fibre and matrix interact at the interface due to Van der Waals forces or hydrogen bonding. Adhesion and diffusion are the two principal phases involved in inter-diffusion bonding mechanism. In the adhesion phase, the fibres and matrix are contacted to ensure adequate wetting. The adhesion is achieved either by covalent, electrostatic and Van der Waals bonding. Adequate wetting results in inter-diffusion of molecules of fibre and matrix. However, the degree of interdiffusion depends on the compatibility between the fibre and the matrix, as well as on the matrix penetration [44].

Adhesive penetration in biocomposites is an important factor determining bond quality. Usually, adhesive flows through the interconnected network of lumens and open pores in the fibres, with flow primarily moving in the direction of least resistance [44]. The distribution of adhesive in composites and the micromechanical properties of the fibre-matrix interface have been studied. Evans et al. [63] used XCT to examine changes in the distribution of melamine-urea-formaldehyde adhesive on wood flakes before and after pressing. The authors reported that resin accumulates in capillary channels within splintered ends of wood flakes., thereby forming an anisotropic discontinuous network by aligning in the same $x-y$ direction as wood flakes [63]. Adhesive penetrations may be nano when it occurs in the cell walls; micro when it occurs in the cell lumen and pit; and macro when it occurs through process-induced cracks.

Figure 7 shows the schematic of the different interfacial bonding mechanisms that occur at different fibre-matrix interfaces. However, it is possible for different types of bonding to occur at the same interface at the same time [64].

\section{Effect of Natural Fibre Modification on Fibre- matrix Interfacial Adhesion and Properties}

There has been much need to understand the mechanisms behind the change in mechanical properties due to natural 


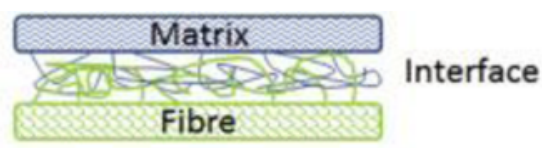

(a)

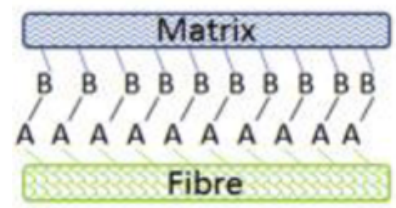

(c)

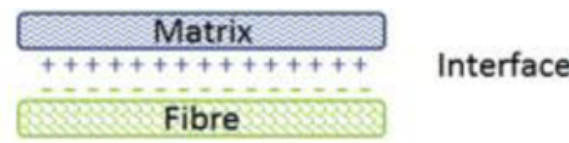

(b)

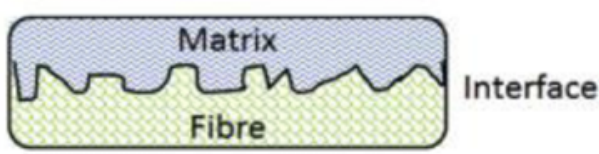

(d)

Figure 7. Fibre-matrix interfacial bonding mechanisms (a) molecular entanglement, (b) electrostatic adhesion, (c) chemical bonding, and (d) mechanical interlocking [44].

fibre modifications, and quantification of the stress transfer ability at the fibre-matrix interface resulting from these modifications [60]. This quantification is difficult mainly due to the small dimension of the fibres, making direct pullout tests extremely cumbersome. This makes SEM the most widely used technique for investigating fibre-matrix interactions at fracture surfaces and polymer distributions in plant fibre composites [44]. Joffre et al. [60] used SEM to observe the fractured surfaces of untreated and acetylated wood fibres/PLA composites. The micrographs showed more long fibres in the matrix for untreated pulp than for treated pulp (Figure 8). The reduction in fibre length at the fracture surface of acetylated samples was explained by an increase in fibre breakage during the crack propagation, which could be due to an increase in the amount of load carried by the fibres [60]. The increased interfacial stress transfer was attributed to better adhesion between the fibre and the matrix. On the other hand, untreated fibres undergo large deformations during moisture changes, which could cause debonding and reduction in the stress transfer ability of the fibre-matrix interface [60].

Several studies have reported on the enhancement of the micromechanical performance of biocomposites following fibre treatments (see Table 2). Lee et al. [65] investigated the effect of natural fibre surface treatments on the IFSS of henequen/polypropylene biocomposites. The IFSS $(\tau)$ was obtained using a single henequen fibre embedded in the PP microdroplet via a microbonding test. A dynamic ultrasonic technique was used to treat the fibre surfaces with $\mathrm{NaOH}$ and tap water, and compared with static soaking technique. The $\tau$ value of untreated henequen/PP biocomposite was remarkably improved by both static and dynamic treatments. The authors reported that the alkali-treated biocomposites exhibited higher $\tau$ values than those treated with water, while the latter was more or less effective to increase the interfacial adhesion between the henequen fibres and the PP matrix [65]. Zafar et al. [66] also reported improved interfacial

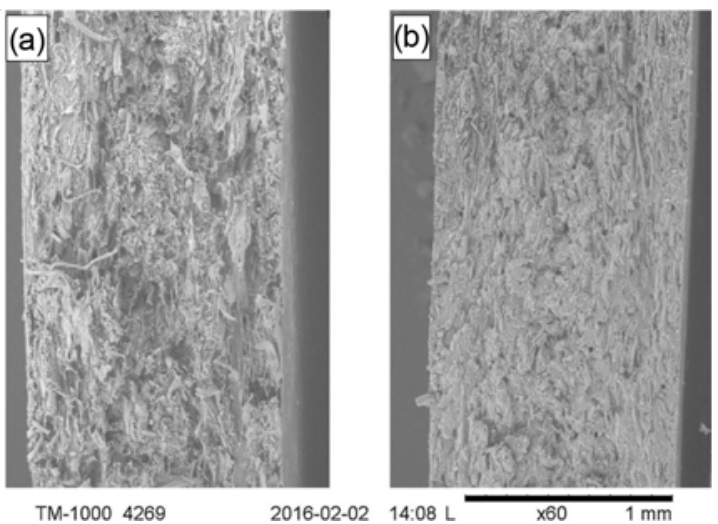

Figure 8. SEM images of the fracture surface of composite soaked in water from (a) untreated pulp fibre and (b) acetylated fibres $(100 \%)$ [60].

adhesion in jute fibre/poly(lactic acid) biocomposites treated with $\mathrm{NaoH}$ and silane coupling agent. It was found that biocomposites treated with a combination of $\mathrm{NaOH}$ and silane agent had the highest $\tau$ value using the single fibre pull-out test [66].

Wong et al. [67] investigated the interfacial adhesion in $\mathrm{NaOH}$ treated bamboo polyester composites using the single fibre pull-out test and supported their results with SEM studies. Treated samples gave higher $\tau$ values and better bonding with the matrix during fibre pull-out. In addition, the $\tau$ value increased with increasing $\mathrm{NaOH}$ concentration. However, as the alkali concentration increases, the percentage improvement decreases [67]. This pattern was also observed by Wang et al. [68]. The authors found that IFSS increased in composite samples treated with 1, 4 and $7 \% \mathrm{NaOH}$ compared to untreated samples (Figure 9). However, there was a decrease in IFSS for samples treated with $7 \%$ compared to those treated with $4 \% \mathrm{NaOH}$. This was probably due to damage of the cellulose crystals and enhancement of 


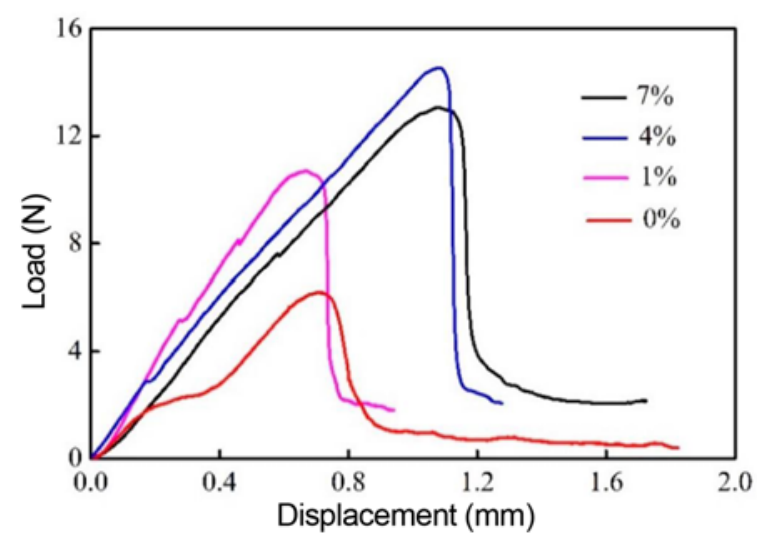

Figure 9. Interfacial property of treated bamboo fibre epoxy composites at different $\mathrm{NaOH}$ concentrations [68].

the polarity by the higher alkali concentration. It was concluded that a large number of elementary fibres separated by the treatment are embedded in the matrix, and are able to uniformly transmit applied loads to the matrix, thereby improving the stress transfer efficiency [68].

According to Wang et al. [68], the force increases linearly with the displacement, while the elastic energy accumulates continuously at the initial phase of the load-displacement curve (Figure 9). At the critical value of the load, the interface is no longer able to withstand the applied force on the fibre, causing a debonding from the matrix. Consequently, the stored elastic energy is released in the creation of an interfacial crack, resulting in a sharp drop in load. A dynamic frictional force sometimes occurs between the fibre and the matrix, causing a fluctuation in the load, as observed early in the loading curve of untreated composites (Figure 9). This could be due to the occurrence of interfacial slipping between the fibre and matrix caused by poor wetting of the fibres, which produces lower IFSS. Other studies also used the pull-out test and SEM to investigate the interfacial property and adhesion in natural fibre/polymer composites [19,69-71]. It was concluded that natural fibre treatment significantly improved the adhesion between fibre and matrix, with a higher IFSS of treated composites during fibre-matrix debonding. This conclusion is based on changes in fibre-matrix interfacial adhesion and improvement in the interfacial property after fibre modification.

\section{Conclusions and Future Prospects}

Biocomposites are a group of engineered products manufactured from natural fibres and polymer matrix. They are increasingly been used in many applications due to their design flexibility, superior properties and aesthetic appeal. As discussed, the major problem between hydrophilic natural fibres and hydrophobic polymers is the presence of hydroxyl groups on the fibre surface, which results in poor interfacial bonding between fibres and matrix, and hence weak micromechanical properties at the matrix interface. The developments of suitable technologies to overcome this limitation are the critical areas to be considered for future development of biocomposites, Currently, natural fibres can be pretreated or even protected by using completely hydrophobic matrix. The goal is to develop methods that are cost-effective, environmentally friendly and technologically feasible. Prior knowledge of the chemical composition of fibres will give an indication on the suitability of such fibres for biocomposite production. The method chosen for treatment will depend on end-use application and resulting effect on the fibres. Fibre coating with a less hydrophobic matrix may lead to better stress transfer but the micromechanical properties will depend on the fibre moisture affinity. With improved interfacial adhesion and shear strength, the biocomposite materials will become durable and possess high flexibility in design and applications. Going forward, understanding the interfacial properties and bonding mechanisms of the biocomposites is the key issue that requires significant research efforts in order to maximise biocomposite applications. More effort should be made on the interfacial characterization of the composites to understand the stress transfer, interaction or adhesion at nanoscale.

\section{Acknowledgements}

The authors would like to thank the National Research Foundation, South Africa for financial support (Grant number: 88598).

Open Access: This article is distributed under the terms of the Creative Commons Attribution 4.0 International License (http://creativecommons.org/licenses/by/4.0/), which permits unrestricted use, distribution, and reproduction in any medium, provided you give appropriate credit to the original author(s) and the source, provide a link to the Creative Commons license, and indicate if changes were made.

\section{References}

1. B. J. Mohr, N. H. El-Ashkar, and K. E. Kurtis, "Fibercement Composites for Housing Construction: State-ofthe-art Review", pp.112-128, Proc. NSF Hous. Res. Agenda Work, 2004.

2. A. A. Moslemi, "Technology and Market Considerations for Fiber Cement Composites", pp.113-129, 11th International Inorganic-Bonded Fiber Composites Conference, 2008.

3. S. O. Amiandamhen, M. Meincken, and L. Tyhoda, Wood Sci. Technol., 52, 653 (2018).

4. S. Misra, M. Misra, S. S. Tripathy, S. K. Nayak, and A. K. Mohanty, Polym. Compos., 23, 164 (2002).

5. A. Komuraiah, N. S. Kumar, and B. D. Prasad, Mech. 
Compos. Mater, 50, 359 (2014).

6. H. Hajiha, M. Sain, and L. H. Mei, J. Nat. Fibers, 11, 144 (2014).

7. A. K. Mohanty, M. Misra, and L. T. Drzal, Compos. Interfaces, 8, 313 (2001).

8. R. Kumar, S. Obrai, and A. Sharma, Pelagia Res. Libr., 2, 219 (2011).

9. J. Cruz and R. Fangueiro, Procedia Eng., 155, 285 (2016).

10. N. M. Stark, Z. Cai, and C. Carll, "Wood Handbook: Wood as an Engineering Material", Centennial edition, Chap.11, pp.11.1-11.28, General Technical Report GTR-190. USDA Forest Service, FPL, Madison, WI, 2010.

11. M. Irle, M. C. Barbu, R. Reh, L. Bergland, and R. M. Rowell in "Handbook of Wood Chemistry and Wood Composites", 2nd ed. (R. M. Rowel Ed.), pp.321-411, CRC Press, London, 2013.

12. J. A. Youngquist, "Wood Handbook - Wood as an Engineering Material”, pp.10.1-10.31, General Technical Report GTR-113, USDA Forest Service, FPL, Madison, WI, 1999.

13. S. R. Karade, M. Irle, and K. Maher, Holzforschung, 57, 672 (2003).

14. A. S. Wagh, ISRN Ceram., 2013, 1 (2013).

15. S. O. Amiandamhen, M. Meincken, and L. Tyhoda, $S N$ Appl. Sci., 1, 910 (2019).

16. P. K. Donahue and M. D. Aro, Constr. Build. Mater., 24, 215 (2010).

17. S. K. Ramamoorthy, M. Skrifvars, A. Persson, and S. Kumar Ramamoorthy, Polym. Rev., 55, 107 (2015).

18. D. Jones, G. O. Ormondroyd, S. F. Curling, C.-M. Popescu, and M.-C. Popescu, "Advanced High Strength Natural Fibre Composites Construction”, pp.23-58, 2017.

19. S. Rizal, Ikramullah, D. Gopakumar, S. Thalib, S. Huzni, and H. Abdul Khalil, Polymers (Basel), 10, 1316 (2018).

20. J. Bhaskar, S. Haq, A. K. Pandey, and N. Srivastava, J. Mater. Environ. Sci., 3, 605 (2012).

21. B. Effah, A. Van Reenen, and M. Meincken, Springer Sci. Rev., 3, 97 (2015).

22. K. G. Kuder and S. P. Shah, Constr. Build. Mater., 24, 181 (2010).

23. S. O. Amiandamhen, M. Meincken, and L. Tyhoda, Ind. Crops Prod., 94, 746 (2016).

24. P. Tittelein, A. Cloutier, and B. Bissonnette, Cem. Concr. Compos., 34, 218 (2012).

25. D. Dai and M. Fan, Ind. Crops Prod., 74, 417 (2015).

26. F. Nindiyasari, E. Griesshaber, T. Zimmermann, A. P. Manian, C. Randow, R. Zehbe, L. Fernandez-Diaz, A. Ziegler, C. Fleck, and W. W. Schmahl, J. Compos. Mater., 50, 657 (2016).

27. X. Li, L. G. Tabil, and S. Panigrahi, J. Polym. Environ., 15, 25 (2007).

28. M. R. Pelaez-Samaniego, V. Yadama, E. Lowell, and R. Espinoza-Herrera, Wood Sci. Technol., 47, 1285 (2013).

29. M. S. Sweet and J. E. Winandy, Holzforschung, 53, 311
(1999).

30. J. L. Shi, D. Kocaefe, and J. Zhang, Holz als Roh - und Werkst., 65, 255 (2007).

31. A. Klüppel and C. Mai, Holzforschung, 66, 493 (2012).

32. M. M. Kabir, H. Wang, T. Aravinthan, F. Cardona, and K.-T. Lau, "Effects of Natural Fibre Surface on Composite Properties : A Review”, pp.94-99, Energy, Environ. Sustain., 2011.

33. K. L. Pickering, M. G. A. Efendy, and T. M. Le, Compos. Part A-Appl. Sci. Manuf., 83, 98 (2016).

34. M. Abdelmouleh, S. Boufi, M. N. Belgacem, and A. Dufresne, Compos. Sci. Technol., 67, 1627 (2007).

35. F. R. Oliveira, L. Erkens, R. Fangueiro, and A. P. Souto, Plasma Chem. Plasma Process., 32, 259 (2012).

36. A. K. Bledzki, H. P. Fink, and K. Specht, J. Appl. Polym. Sci., 93, 2150 (2004).

37. T. E. Amidon, C. D. Wood, A. M. Shupe, Y. Wang, M. Graves, and S. Liu, J. Biobased Mater. Bioenergy, 2, 100 (2008).

38. M. R. Pelaez-Samaniego, V. Yadama, T. Garcia-Perez, E. Lowell, and T. Amidon, Holzforschung, 68, 807 (2014).

39. M. A. Sawpan, K. L. Pickering, and A. Fernyhough, Compos. Part A-Appl. Sci. Manuf., 42, 888 (2011).

40. N. P. G. Suardana, Y. Piao, and J. K. Lim, Mater. Phys. Mech., 11, 1 (2011).

41. B. Wang, S. Panigrahi, L. Tabil, and W. Crerar, J. Reinf. Plast. Compos., 26, 447 (2007).

42. M. M. Kabir, H. Wang, F. Cardona, and T. Aravinthan, "Incorporating Sustainable Practice in Mechanics and Structures of Materials", pp.1-6, 2008.

43. M. M.-U. Haque, M. A. A. Zaman, M. H. Rahaman, M. Z. Hossain, and M. Maniruzzaman, Int. J. Mater. Sci. Appl., 3, 106 (2014).

44. Y. Zhou, M. Fan, and L. Chen, "Interface and Bonding Mechanisms of Plant Fibre Composites: An Overview", Vol. 101, Elsevier Ltd., 2016.

45. P. F. Vena, J. F. Görgens, and T. Rypstra, Cellul. Chem. Technol., 44, 153 (2010).

46. D. M. de Carvalho, O. Sevastyanova, J. H. de Queiroz, and J. L. Colodette, Energy Convers. Manag., 124, 315 (2016).

47. P. F. Vena, M. Brienzo, M. P. García-Aparicio, J. F. Görgens, and T. Rypstra, Holzforschung, 67, 863 (2013).

48. G. Faludi, G. Dora, K. Renner, J. Móczó, and B. Pukánszky, Compos. Sci. Technol., 89, 77 (2013).

49. S. Mohanty and S. K. Nayak, J. Appl. Polym. Sci., 102, 3306 (2006).

50. A. M. Daniel, "Interfacial Properties of Fibre Reinforced Ceramic Matrix Composites", Ph.D. Thesis, University of Warwick, 1994.

51. F. A. Ramirez, L. A. Carlsson, and B. A. Acha, Compos. Part A-Appl. Sci. Manuf., 40, 679 (2009).

52. Z. Ding, B. Dong, F. Xing, N. Han, and Z. Li, Ceram. Int, 38, 6281 (2014).

53. C. H. Hsueh, Mater. Sci. Eng. A, 149, 1 (1991). 
54. R. B. Yallee and R. J. Young, Compos. Sci. Technol., 58, 1907 (1998).

55. S. Zhifei, C. Yanhua, and Z. Limin, Compos. Sci. Technol, 65, 1203 (2005).

56. H. Chi, "Interfacial Properties of Chemical Bonded Phosphate Ceramics and Sugar Maple", MSc Thesis, Washington State University, 2012.

57. B. A. Budiman, K. Takahashi, K. Inaba, and K. Kishimoto, J. Compos. Mater., 49, 465 (2015).

58. J. Koyanagi, S. Ogihara, H. Nakatani, T. Okabe, and S. Yoneyama, Adv. Compos. Mater., 23, 551 (2014).

59. F. A. Kamke, J. A. Nairn, L. Muszynski, J. L. Paris, M. Schwarzkopf, and X. Xiao, Wood Fiber Sci., 46, 15 (2014).

60. T. Joffre, K. Segerholm, C. Persson, S. L. Bardage, C. L. Luengo Hendriks, and P. Isaksson, Ind. Crops Prod., 95, 43 (2017).

61. H. Chi and K. R. Englund, Holzforschung, 68, 575 (2014).

62. F. L. Matthews and R. D. Rawlings, "Composite Materials: Engineering and Science", 2nd ed., Woodhead Publishing Ltd., Cambridge, 1999.

63. P. D. Evans, O. Morrison, T. J. Senden, S. Vollmer, R. J. Roberts, A. Limaye, C. H. Arns, H. Averdunk, A. Lowe, and M. A. Knackstedt, Int. J. Adhes. Adhes., 30, 754 (2010).

64. G. W. Beckermann and K. L. Pickering, Compos. Part A Appl. Sci. Manuf., 39, 979 (2008).

65. H. S. Lee, D. Cho, and S. O. Han, Macromol. Res., 16, 411 (2008).

66. M. T. Zafar, S. N. Maiti, and A. K. Ghosh, Fiber. Polym., 17, 266 (2016).

67. K. J. Wong, B. F. Yousif, and K. O. Low, Proc. IMechE Part I-J. Mater. Des. Appl., 224, 139 (2010).

68. F. Wang, M. Lu, S. Zhou, Z. Lu, and S. Ran, Molecules, 24, 2682 (2019).

69. Y. Chang, T. Sun, C. Fan, and X. Zhou, Compos. Interfaces, 25, 981 (2018).

70. B. Fathi, M. Foruzanmehr, S. Elkoun, and M. Robert, J. Compos. Mater, 53, 2229 (2019).

71. A. Širvaitienė, V. Jankauskaitė, P. Bekampienè, and A. Kondratas, Fibres Text. East. Eur., 21, 123 (2013).

72. I. Sable, U. Grinfelds, A. Jansons, L. Vikele, I. Irbe, A Verovkins, and A. Treimanis, Bioresources, 7, 1771 (2012).

73. T. Räisänen and D. Athanassiadis, "Basic Chemical Composition of the Biomass Components of Pine, Spruce and Birch", pp.1-4, Forest Refine, 2013.

74. M. Ramírez, J. Rodríguez, C. Balocchi, M. Peredo, J. P. Elissetche, R. Mendonça, and S. Valenzuela, J. Wood Chem. Technol., 29, 43 (2009).

75. J. Rencoret, A. Gutiérrez, and J. C. del Río, "Chemical
Composition of Different Eucalyptus Wood Species used for Paper Pulp Manufaturing", pp.447-450, 9th European Workshop on Lignocellulosics and Pulp, Vienna, Austria, August 27-30, Advances in Chemistry and Processing of Lignocellulosics, 2006.

76. A. Bismarck, I. Aranberri-Askargorta, J. Springer, T. Lampke, B. Wielage, A. Stamboulis, I. Shenderovich, and H.-H. Limbach, Polym. Compos., 23, 872 (2002).

77. P. Cappelletto, M. Brizzi, F. Mongardini, B. Barberi, M. Sannibale, G. Nenci, M. Poli, G. Corsi, G. Grassi, and P. Pasini, Ind. Crops Prod., 13, 101 (2001).

78. M. Jonoobi, J. Harun, A. Shakeri, M. Misra, and K. Oksmand, BioResources, 4, 626 (2009).

79. S. Karakus, D. N. Roy, and K. Goel, J. Wood Chem. Technol., 21, 157 (2001).

80. E. F. Alves, S. K. Bose, R. C. Francis, J. L. Colodette, M. Iakovlev, and A. Van Heiningen, Carbohydr. Polym., 82, 1097 (2010).

81. C. A. Cardona, J. A. Quintero, and I. C. Paz, Bioresour. Technol., 101, 4754 (2010).

82. C. A. Rezende, M. A. de Lima, P. Maziero, E. R. Deazevedo, W. Garcia, and I. Polikarpov, Biotechnol. Biofuels, 4, 1 (2011).

83. A. Rakha, P. Åman, and R. Andersson, J. Cereal Sci., 54, 324 (2011).

84. S. Boufi and A. Gandini, RSC Adv., 5, 3141 (2015).

85. G. M. Scott and A. Smith, "Sludge Characteristics and Disposal Alternatives for the Pulp and Paper Industry", pp.269-279, Proc. Int. Environ. Conf., 1995.

86. M. J. Jackson and M. A. Line, J. Agric. Food Chem., 45, 2354 (1997).

87. J. Roux, G. H. J. Kemp, and M. J. Wingfield, South African For. J., 174, 35 (1995).

88. P. B. Venter, N. D. Senekal, G. Kemp, M. Amra-Jordaan, P. Khan, S. L. Bonnet, and J. H. Van Der Westhuizen, Phytochemistry, 83, 153 (2012).

89. K. Panyasart, N. Chaiyut, T. Amornsakchai, and O. Santawitee, Energy Procedia, 56, 406 (2014).

90. U. Nirmal, S. T. W. Lau, and J. Hashim, J. Compos., 2014, 350737 (2014).

91. Z. Ren, C. Wang, Q. I. Zuo, S. Hussain, and S. Yousfani, Sains Malaysiana, 48, 173 (2019).

92. H.-S. Kim, B.-H. Lee, S.-W. Choi, S. Kim, and H.-J. Kim, Compos. Part A Appl. Sci. Manuf., 38, 1473 (2007).

93. K. Okubo, T. Fujii, and N. Yamashita, JSME Int. J., 48, 199 (2005).

94. H. Mohit and V. A. M. Selvan, Compos. Interfaces, 25, 629 (2018). 